Laser Chem., 1999, Vol. 19, pp. 279-282

Reprints available directly from the publisher Photocopying permitted by license only
(C) 1999 OPA (Overseas Publishers Association) N.V. Published by license under the Harwood Academic Publishers imprint, part of The Gordon and Breach Publishing Group.

\title{
TIME-RESOLVED INFRARED SPECTROSCOPY OF BINUCLEAR RHENIUM (I) POLYPYRIDYL COMPLEXES IN SOLUTION
}

\author{
L. C. ABBOTT ${ }^{\mathrm{a}}$, C. J. ARNOLD ${ }^{\mathrm{a}}$, K. C. GORDON ${ }^{\mathrm{b}}$, \\ R. E. HESTER ${ }^{a}$, J. N. MOORE ${ }^{a, *}$, R. N. PERUTZ ${ }^{a}$ \\ and T.-Q. YE ${ }^{\mathrm{a}}$ \\ ${ }^{a}$ Chemistry Department, The University of York, Heslington, \\ York, YO1 5DD, UK; \\ ${ }^{\mathrm{b}}$ Chemistry Department, University of Otago, P. O. Box 56, \\ Dunedin, New Zealand
}

(Received 30 April 1997)

A series of four binuclear rhenium (I) complexes of the general form $\left[\operatorname{Re}(\mathrm{CO})_{3} \mathrm{Cl}\right]_{2} \mathrm{BL}$, where $\mathrm{BL}$ is a polypyridyl bridging ligand, have been studied using ultrafast timeresolved UV/visible (TRVIS) and infrared (TRIR) spectroscopies. Visible excitation produces a metal-to-ligand charge-transfer (MLCT) excited state. Kinetic measurements show that the lifetime of this MLCT state varies between 100 and $1900 \mathrm{ps}$, depending on the structure of the bridging ligand. TRIR difference spectra show that each complex forms a similar MLCT state which has mixed valence character.

Keywords: Time-resolved infrared spectroscopy; time-resolved UV/visible spectroscopy; ultrafast; metal-to-ligand charge transfer; excited states; rhenium (I) polypyridyl complexes

\section{INTRODUCTION}

Steady-state studies have shown that each of the complexes $\left[\mathrm{Re}(\mathrm{CO})_{3} \mathrm{Cl}\right]_{2} \mathrm{BL}(\mathrm{BL}=\mathrm{BL} 1, \mathrm{BL} 2, \mathrm{BL} 4$, or $\mathrm{dpq})$, as shown in Figure 1, has a strong visible absorption band at $500-600 \mathrm{~nm}$ which has been assigned to a MLCT transition [1]. The aim of this work was to use

${ }^{*}$ Corresponding author. 

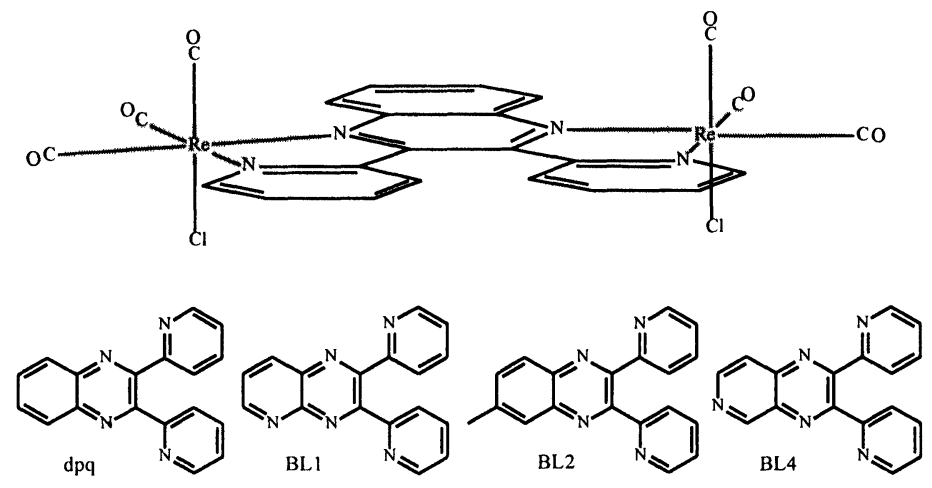

FIGURE 1 Structures of the $\left[\mathrm{Re}(\mathrm{CO})_{3} \mathrm{Cl}\right]_{2} \mathrm{BL}$ complexes.

ultrafast TRVIS and TRIR to study the structure and dynamics of the MLCT state for each complex.

\section{EXPERIMENTAL}

The ultrafast laser apparatus has been described previously [2]. The complexes were studied in dichloromethane solution, and $200 \mathrm{fs}$ pulses at $604 \mathrm{~nm}$ were used for photolysis.

\section{RESULTS AND DISCUSSION}

The TRVIS difference spectrum was found to be similar for each complex. The TRVIS kinetics showed that the lifetimes of the MLCT states vary between ca. 100 and 1900 ps, depending on the identity of the bridging ligand and increasing in the order $\mathrm{BL} 1<\mathrm{BL} 4<\mathrm{dpq}$ $<$ BL2.

The kinetics observed by TRIR were found to be similar to those observed by TRVIS spectroscopy. In addition to decay of the excited state to the ground state, the TRIR kinetics also showed clearly the presence of a fast component of ca. $5 \mathrm{ps}$, as illustrated in Figure 2, which may be assigned to vibrational relaxation in the excited state. TRIR difference spectra recorded in the $\nu(\mathrm{CO})$ region showed excited state absorption to both higher and lower wavenumbers than the 


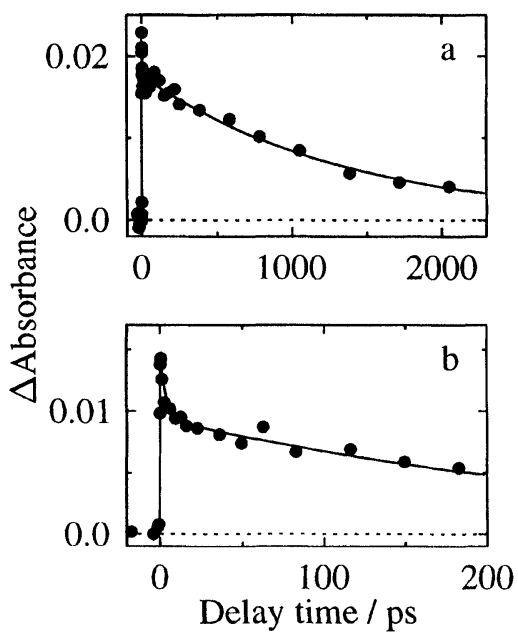

FIGURE 2 TRIR kinetics observed on $604 \mathrm{~nm}$ photolysis of (a) $\left[\operatorname{Re}(\mathrm{CO})_{3} \mathrm{Cl}\right]_{2} \mathrm{dpq}$, measured at $1971 \mathrm{~cm}^{-1}$ and fitted to a bi-exponential function with lifetimes of 5 and $1350 \mathrm{ps}$, and (b) $\left[\operatorname{Re}(\mathrm{CO})_{3} \mathrm{Cl}\right]_{2} \mathrm{BL} 4$, measured at $1889 \mathrm{~cm}^{-1}$ and fitted to a bi-exponential function with lifetimes of 5 and 300 ps.

ground-state absorption bands. This may be interpreted as the formation of an asymmetric, mixed-valence MLCT state. The magnitudes of the up-shifts and down-shifts, relative to the ground state absorption bands, were found to be similar for each complex, suggesting that the structures of the excited states also are similar.

\section{CONCLUSIONS}

Each of the four binuclear rhenium (I) polypyridyl complexes studied here forms a short-lived MLCT state following visible photolysis. TRIR spectra show that the structures of the MLCT states are similar, with oxidation of one metal centre and reduction of the bridging ligand. The lifetime of the MLCT state is found to be strongly dependent on the structure of the bridging ligand in the complex.

\section{Acknowledgements}

We thank EPSRC for research grant, studentship, and Advanced Fellowship (JNM) support. 


\section{References}

[1] Simpson, T. J. and Gordon, K. C. (1995). Inorg. Chem., 34, 6323.

[2] Ye, T.-Q., Arnold, C. J., Pattison, D. I., Anderton, C. L., Dukic, D., Perutz, R. N., Hester, R. E. and Moore, J. N. (1996). Appl. Spectrosc., 50, 597. 